\title{
Barriers to Student Entrepreneurship in South Africa
}

\author{
Richard Shambare \\ Tshwane University of Technology, South Africa \\ shambarar@tut.ac.za
}

\begin{abstract}
As rising unemployment levels continually erode job opportunities in South Africa, it is sensible to assume that entrepreneurship would be considered as the next-best career option; however, university graduates show very little interest in becoming entrepreneurs. Having observed this disinterest, South African economic policies have put in place initiatives encouraging youth entrepreneurship; however, these have failed to significantly affect the willingness to engage in entrepreneurial activities. It is against this background that this paper investigates barriers to entrepreneurship as experienced by students. A survey of 235 university students was conducted. Their views regarding entrepreneurship were collected by means of self-completion questionnaires and studied using cluster analysis. It was concluded that a taxonomy of two distinct categories of student exist - sceptics and optimists - based on respondents' predispositions to entrepreneurship barriers. The author identifies the themes that underlie the formation of the taxonomy, namely, family and social influence, exposure to entrepreneurial activity, entrepreneurial support, and education. The paper concludes with a discussion of practical solutions and strategies to mitigate the problem of a lack of student entrepreneurship.
\end{abstract}

Keywords: Education, entrepreneurship, entrepreneurship education, universities, South Africa

\section{Introduction}

The issue of youth unemployment is a growing global problem. In the recent past, protests by unemployed youths have dominated news headlines in the United Kingdom (Apps, 2011), Spain (Kane, 2013), the Eurozone (Robertson, 2013), and South Africa (Chauke, 2011). In response to the unemployment question, policymakers encourage school leavers to embark on self-employment and entrepreneurial ventures (Shane, 2008). Considering the dwindling employment opportunities globally, such a policy position seems to be a reasonable argument and well-justified(Sowetan, 2012). The South African government is among those that consider the escalation of youth entrepreneurship as a development imperative (Republic of South Africa, 2012). Consequently, numerous small-business agencies, such as the National Youth Development Agency (NYDA) and Small Enterprise Development Agency (SEDA), have been established. Through its National Development Plan (NDP), the South African government envisages collaboration of these agencies with institutions of higher learning to transform South Africa into an entrepreneurial society(Republic of South Africa, 2012). This vision includes concerted efforts towards providing support and infrastructure (e.g. loan facilities and incubation services) to budding entrepreneurs (Republic of South Africa, 2012; UNDP, 2007).

The Global Entrepreneurship Monitor (2011) acknowledges that South Africa has one of the best entrepreneurial support systems among the emerging economies. Despite this, the disappointing reality is that South African youth entrepreneurship levels lag behind international and regional standards (Global Entrepreneurship Monitor, 2011; Lennox, 2013). A major reason for this appears to be the attitudes of graduates towards entrepreneurship. The Global Entrepreneurship Monitor (2011) statistics reveal a general lack of interest among the youth to engage in new venture start-ups (NVSUs). Given the critical role of youth entrepreneurship in the attainment of development goals and as a means to arrest inflating unemployment levels, this emerging trend of university graduates' lack of interest to engage in entrepreneurial activity is fast becoming a major socio-economic challenge for the country(Lennox, 2013; Republic of South Africa, 2012). Against this background, it was therefore opportune to investigate reasons underlying low levels of entrepreneurial activity by university graduates.

Research objectives: Drawing from the extant literature(Ebewo and Shambare, 2012; Makgosa and Ongori, 2012; Solymossy and Hisrich, 1998; van der Walt and van der Walt, 2008; Yaghoubi, 2010), it was observed that university students and graduates experience a multitude of barriers limiting their participation in entrepreneurial activities. For that reason, this study investigates the nature of barriers 
and the extent to which these limit entrepreneurial activities among university students. Consequently, the following research questions were investigated:

RQ1: Which barriers most discourage students from engaging in entrepreneurship?

RQ2: Are these barriers experienced differently across the student population?

The potential value of this research is that, by examining entrepreneurial barriers as experienced by students, insights are gained that may inform actionable strategies on how universities and policymakers could better respond to the problem. To explore these research issues, the theoretical context of entrepreneurship barriers is explored next, followed by a description of the research methodology applied in the study, presentation of results, and finally, the paper concludes by discussing the implications of the findings.

\section{Literature Review}

Youth entrepreneurship: a global problem: Although the emerging trend of university graduates 'lack of interest and inability to engage in entrepreneurial activity is fast becoming a global problem(Global Entrepreneurship Monitor, 2011; Kesler and Hout, 2010; Makgosa and Ongori, 2012; Massad and Tucker, 2009; Yaghoubi, 2010),it is most severely experienced in developing countries. In South Africa, for example, rising unemployment levels, in excess of 25 per cent (Statistics South Africa, 2013), indicate the declining traditional job opportunities for tertiary education graduates(Chauke, 2011; Ebewo and Shambare, 2012). It is therefore sensible to assume that entrepreneurship is a solution to the unemployment problem. However, graduates show very little interest in becoming entrepreneurs, even in the face of policies and programmes aimed at promoting entrepreneurship(Makgosa and Ongori, 2012). Nevertheless, promoting entrepreneurship, particularly within the small, micro, and medium enterprises (SMME) sector, is identified as an imperative for development in South Africa (Global Entrepreneurship Monitor, 2011; van der Walt and van der Walt, 2008). As such, there have been calls to transform the higher education sector to accommodate entrepreneurship education (Strydom and Adams, 2009). Policymakers view training students to become employers as a key national priority, especially to arrest joblessness(Statistics South Africa, 2013). In support of this view, Du Pre (2009) specifically illustrates the efficacy of tertiary education in stimulating entrepreneurial attitudes. Research shows that universities are ideally placed to address this problem (Du Pre, 2009; Greve, 1995; Republic of South Africa, 2012).

Student lack of interest in entrepreneurship: Authors such as van der Walt and van der Walt (2008) caution that, even though there is a strong correlation between tertiary education and the propensity to engage in entrepreneurship activities, acquiring university education does not necessarily convert an individual into an entrepreneur. A significant number of students prefer the guaranteed income of formal employment as opposed to the risks associated with entrepreneurship (Ebewo and Shambare, 2012; Makgosa and Ongori, 2012). Although authors such as Yaghoubi (2010) acknowledge a multitude of barriers to entrepreneurship as major impediments to student entrepreneurship, strategies that universities can employ to mitigate these barriers are not clearly articulated in the literature. This therefore provides further justification for this research. To understand the phenomenon of youth entrepreneurship, many authors have studied the link between students' perceptions and entrepreneurial intentions (Makgosa and Ongori, 2012), the prevalence of business-planning skills(Ebewo and Shambare, 2012), and entrepreneurial promotion (Yaghoubi, 2010) as factors that influence entrepreneurial activity. These authors clearly demonstrate that students are less likely to be motivated to choose entrepreneurship as a career path in conditions where they lack business management skills, including planning skills, lack support and are not exposed to real business scenarios, they are less likely to be motivated to choose entrepreneurship as a career path.

The entrepreneurship education agenda in universities therefore is viewed as a catalyst for stimulating entrepreneurial intentions(Du Pre, 2009; Global Entrepreneurship Monitor, 2011; Jones and English, 2005; Massad and Tucker, 2009; van der Walt and van der Walt, 2008). Lekoko(2011:10) asserts that the higher education system plays a critical role in developing entrepreneurs, in that universities have the potential to promote entrepreneurial capacities, shape enterprising mind sets and, more importantly, stimulate entrepreneurial intentions. This is consistent with Yaghoubi (2010) and Makgosi and Ongari (2012), who observed a positive link between education and entrepreneurship promotion. Building on the above premise, this author argues that, although traditional university education is instrumental in stimulating entrepreneurship awareness, overemphasis on it alone without practical entrepreneurship 
training fails to equip students with tangible business skills. The outcome of this overemphasis on theoretical education results in a superficial view of entrepreneurship; this further exacerbates the problem by creating the illusion that university graduates are ready for entrepreneurship when in fact they are not. In most cases, they lack experience and technical know-how of starting and operating a business beyond the 'theoretical' knowledge. The reality is that would-be entrepreneurs experience numerous challenges and barriers when setting up their businesses. This paper therefore investigates the barriers to entrepreneurship promotion as experienced by students.

Entrepreneurship barriers (EB): Given the reluctance of students to engage in new entrepreneurial ventures, many authors, including Yaghoubi (2010) and Lekoko (2011) focus on understanding the challenges that exist in translating university education into entrepreneurial activity. Findings from these studies identify four major shortcomings associated with universities' current teaching methods as they relate to entrepreneurship promotion. These barriers contribute to an impoverished interest in pursuing a career in entrepreneurship. These are briefly discussed below.

Inappropriate syllabi and content: For course content in any education setting to be useful, it should be in line with the economic realities of the country(Republic of South Africa, 2012). For instance, in South Africa the NDP envisages that higher education must contribute towards the creation and development of entrepreneurs. At a micro- or individual-level the syllabus must be comprehensive enough to prepare individual students to acquire practical entrepreneurial skills and knowledge. Ideally, a business management student, upon graduation, should be sufficiently qualified to draft a decent business plan(Ebewo and Shambare, 2012). The reality though is that university graduates are not only illprepared for business, they are often not even qualified enough for the labour market (Sowetan, 2012). Clearly, this indicates inappropriate educational content in the area of entrepreneurial education.

Inappropriate teaching methods: While content is important, how it is taught is equally vital. Teaching methods determine students' level of engagement(Shambare, 2011). Thus, to promote higher learning, universities should employ teaching methods that allow for practical application of learnt material as well as holistic development of skill-sets required. In the context of entrepreneurship, this relates to teaching both theoretical and practical aspects of businesses(Strydom and Adams, 2009). Efficient teaching methods go beyond reciting formulae in textbooks, they empower students to develop free and creative thinking in the application of knowledge and theory in the real world (Massad and Tucker, 2009).

Lack of entrepreneurial support: While developing SMMEs is widely recognised as one of the important objectives of business education at the tertiary level(Du Pre, 2009), universities appear to drag their feet in proactively developing student-driven businesses. A classic example is the genesis of Facebook. Harvard University almost "killed" what has become one of the most influential information communications technology (ICT) companies in the world today(Facebook.com, 2012).This suggests that, despite claiming support and commitment for new venture creation, many universities fail to live up to this ideal. As a result, students do not enjoy university support when trying out "crazy "business ideas (Greve, 1995). In contrast to the entrepreneurship mantra espoused by many universities, it appears as if students are being trained to become employees (Gaidzanwa, 2003). Consequently, valuable opportunities to experiment on small business ventures, and to experience first-hand what is it means to be an entrepreneur, are being lost(Massad and Tucker, 2009).

Students' lack of exposure: Students' lack of exposure to entrepreneurial concepts and realities within the South African context can be defined in two distinct ways. Firstly, as a result of widespread poverty, students often come from very poor backgrounds and are generally not exposed to the wider world around them (UNDP, 2007). In addition, because of the apartheid legacy, black students' entrepreneurial intentions are 50 per cent lower than those of other ethnic groups (Global Entrepreneurship Monitor, 2011). Secondly, as a result of apartheid's Bantu education system, universities today are enrolling illprepared students(Du Pre, 2009). This, coupled with under-funded and under-resourced universities, means that many universities cannot afford to provide the appropriate training to increase students' exposure.

\section{Methodology}

A structured survey method was used to collect data from a sample of students at a metropolitan university campus in Pretoria(Blumberg, Cooper and Schindler, 2011). A self-completion questionnaire 
was used to collect data between January and March 2012.Three undergraduate students were trained as research assistants and assisted with data collection. In order to allow access to a relatively large pool of potential respondents, research assistants were positioned at strategic locations where student traffic on campus is generally high, for instance near cafeterias, libraries, computer labs, and sporting facilities.

Questionnaire: To reliably identify and measure barriers to entrepreneurship as experienced by university students, the author drew insights from past research (Ebewo and Shambare, 2012; Global Entrepreneurship Monitor, 2011; Makgosa and Ongori, 2012; Yaghoubi, 2010), from which a set of theoretical entrepreneurship barriers was developed and subsequently tested. Of these, Yaghoubi's (2010) barriers to entrepreneurship model was considered to be the most relevant in explaining the South African situation under study. Accordingly, specified barriers described in these studies were incorporated with those from Yaghoubi's (2010) to develop a questionnaire for this study. It was also prudent to test both content and face validity. The former was assured by means of a comprehensive literature review; the latter through consultative discussions with practicing entrepreneurs and academics (Dulewics, Higgs and Slaski, 2003). A pilot test was conducted with 20 undergraduate students to ensure that questionnaire items would be comprehensible to the target respondents, with resulting input, mostly relating to grammar usage, incorporated into the final questionnaire. The questionnaire consisted of three sections: demographics, entrepreneurship knowledge, and entrepreneurship barriers scale (see Table 1). The entrepreneurship barriers scale was made up of 16questions measuring the four identified barriers (inappropriate teaching methods, lack of entrepreneurial support, inappropriate syllabi and content, and students' lack of exposure to business and entrepreneurship).

Table 1: Measuring Instrument

\begin{tabular}{lll}
\hline Section & Measurement Instruments & Source \\
\hline Part I & Demographics & Developed for this research \\
Part II & Entrepreneurship knowledge & Gartner (1988); Greve (1995); Makgosa and Ongori (2012) \\
Part III & Entrepreneurship barriers scale & $\begin{array}{l}\text { Ebewo and Shambare (2012); Makgosa and Ongori (2012); } \\
\text { Yaghoubi (2010) }\end{array}$ \\
\hline
\end{tabular}

Although research assistants explained the purpose of the study as well as the contents of the questionnaire, a covering letter explaining the purpose of the study, the confidentiality agreement and instructions for completing the questionnaire, was attached to every questionnaire. These instructions were also provided at the beginning of each section together with a brief explanation of the measurement scale.

Measuring Entrepreneurship Barriers: Using Cronbach's alpha $(\alpha)$ coefficient, the measuring instruments were tested for internal consistency. Item selection and scale purification using inter-item and item-to-total correlations were used to enhance internal consistency. Except for the demographic information, all sub-scales (see Table 2) were tested for reliability. Cronbach's alphas ranged from 0.517 (Student exposure) to 0.770 (Teaching methods); these indicate an acceptable reliability measure for the questionnaire.

Table 2: Cronbach's alpha ( $\alpha$ ) for the sub-scales

\begin{tabular}{lll}
\hline $\begin{array}{l}\text { Instrument } \\
\text { (Sub-scale) }\end{array}$ & Cronbach's alpha $(\boldsymbol{\alpha})$ & No. of items retained \\
\hline Inappropriate teaching methods & 0.770 & 5 \\
Lack of entrepreneurial support & 0.727 & 5 \\
Syllabus and course content & 0.646 & 3 \\
Students lack of exposure \& interest & 0.517 & 3 \\
\hline
\end{tabular}

Data analysis: Since a structured questionnaire was utilised to collect data, statistical analyses were performed. All returned questionnaires were checked for completeness. Those with more than 3 missing responses on the Likert scale were discarded. However, those with no more than two incomplete biographical data responses were included in the study, as some of the questions in this section requested sensitive personal information that respondents chose to omit. SPSS version 20 was used for data analysis. The following statistical analyses were employed:

- Descriptive statistics to describe the data and the sample;

- Factor analysis to establish the dimensions (or factors) that exist in the various sub-scales; 
- Cluster analysis to determine if university students can be classified into different groups in terms of the entrepreneurship barriers they experience.

Sampling: The present study concentrated on business management students. This meant that only students registered towards a qualification in the Faculty of Management Sciences at the Tshwane University of Technology were included in the sample. Two reasons influenced this choice. Firstly, it is generally accepted that management schools are better equipped to train entrepreneurs in that their students, naturally, are more exposed to entrepreneurship and entrepreneurial processes and hence should exhibit more inclination towards entrepreneurship. As such, it was opportune to put this supposition to empirical test. Secondly, business and management students represent a significant, if not a majority, of the student population in many South African institutions of higher learning, hence the number of students is potentially large.

Convenience sampling was utilised to collect responses (Blumberg et al., 2011). Prior to participating, respondents were screened to ensure that they were indeed registered business management students. In addition, within the questionnaire itself, two screening questions were used to determine not only the participants' faculty of registration but also the department within which they were enrolled. Questionnaires were handed out and participants were allowed to complete the questionnaires in their free time and deposit the completed questionnaires in collection boxes located at the above-mentioned locations. In total, 450 questionnaires were distributed. Some 272 questionnaires were returned. 235 questionnaires were fully completed and usable for analysis. More females (approximately 60 per cent) participated than males. Table 1 illustrates that the vast majority (95 per cent) of participants were undergraduate students; their mean age was 21.5 years, with a standard deviation of 3.3 years.

Table 3: Demographic profile

\begin{tabular}{lll}
\hline Demographic characteristics & Per cent (\%) \\
\hline Gender & Male & 40 \\
& Female & 60 \\
Education & Undergraduate & 95 \\
& Postgraduate & 5 \\
Study status & Part-time & 8 \\
& Full-time & 92 \\
\hline
\end{tabular}

\section{Results and Discussion}

The results are presented in the order of the research questions. First, a descriptive analysis of the barriers and their effect across demographic profiles are discussed. Past literature demonstrates that there are four key barriers to entrepreneurship promotion; this paper tests how these barriers limit students and youths' participation in entrepreneurship activities.

RQ1: Which barriers most discourage students from engaging in entrepreneurship?

To test the above question, first it was prudent to test the structure of these barriers against those posited by the 'barriers to entrepreneurship model'(Yaghoubi, 2010).According to Yaghoubi, the entrepreneurship barriers (EB) scale contains four subscales which load independently as factors: lack of entrepreneurial support, teaching methods, lack of exposure, and course content. Factor analysis utilising principal component analysis (PCA) (Field, 2009)was performed to test both construct validity(Dulewics et al., 2003)and the latent variables (EB barriers) as hypothesised in the EB theory. The factor analysis diagnostics were satisfactory (KMO $=0.824$; Bartlett's Test of Sphericity $X^{2}=890.6 ; p<0.000$ ), hence it was appropriate to proceed with PCA. Subsequently, a four-factor (latent variables) solution explaining 56 per cent of the variance was extracted. All items loaded onto their respective factors, as explained by the theory. Teaching methods items loaded onto Factor 1. Factor 2 consisted of items related to entrepreneurial support. Deficiencies with the syllabus and lack of students' exposure loaded onto Factors 3 and 4, respectively. These results confirmYaghoubi (2010) findings - that the above-mentioned barriers to entrepreneurship do indeed exist. 
Table 4: Four-factor solution of EB responses

\begin{tabular}{|c|c|c|c|c|c|}
\hline & $\begin{array}{l}\text { Factor } 1 \\
\text { Teaching } \\
\text { Methods }\end{array}$ & $\begin{array}{l}\text { Factor } 2 \\
\text { Support }\end{array}$ & $\begin{array}{l}\text { Factor } 3 \\
\text { Syllabus }\end{array}$ & $\begin{array}{l}\text { Factor } 4 \\
\text { Exposure }\end{array}$ & Communalities \\
\hline EB 8 & .749 & & & & .630 \\
\hline EB 7 & .749 & & & & .622 \\
\hline EB 6 & .704 & & & & .610 \\
\hline EB 9 & .673 & & & & .484 \\
\hline EB 5 & .503 & & & & .462 \\
\hline EB 13 & & .762 & & & .649 \\
\hline EB 16 & & .692 & & & .503 \\
\hline EB 12 & & .645 & & & .501 \\
\hline EB 15 & & .625 & & & .601 \\
\hline EB 14 & & .609 & & & .510 \\
\hline EB 3 & & & .781 & & .644 \\
\hline EB 4 & & & .691 & & .576 \\
\hline EB 2 & & & .645 & & .520 \\
\hline EB 1 & & & & .699 & .497 \\
\hline EB 11 & & & & .619 & .633 \\
\hline EB 10 & & & & .605 & .521 \\
\hline Eigenvalues & 4.874 & 1.594 & 1.406 & 1.088 & (Total) \\
\hline$\%$ of variance & 30.464 & 9.961 & 8.788 & 6.800 & 56.012 \\
\hline Cronbach's alpha $(\alpha)$ & 0.770 & 0.727 & 0.646 & 0.517 & \\
\hline
\end{tabular}

The sub-scales' internal consistencies, as measured by Cronbach's alphas, ranged from 0.517 to 0.770 (see Table 3); these alphas show acceptable tolerances of reliability of greater than 0.5 (Field, 2009; Pallant, 2010). Thus, the high reliability loadings as well as high factor loadings within each factor (latent variable) provides further support for the existence of the entrepreneurship barriers in South Africa. These findings clearly support and corroborate those observed in earlier studies(c.f. Du Pre, 2009; Ebewo and Shambare, 2012; Global Entrepreneurship Monitor, 2005; 2011; Kane, 2013; Kesler and Hout, 2010; Lekoko, 2011; Makgosa and Ongori, 2012). Within this study, it was not enough just to identify the entrepreneurship barriers limiting youth entrepreneurship, ranking these in order of severity as reported by students was also meaningful. The latent variables or factors identified in Table 3 were further analysed.

Descriptive analysis, as shown in Table 4 was quite useful. Respondents rated their views pertaining to the extent they felt each of the EB scales limited their capability to become entrepreneurs. A Likert Scale (1=Strongly Disagree; 5=Strongly Agree) was used. Following the factor analysis, the resultant factors (Table 3) were recorded into four latent composite variables, and subjected to further analysis. Lack of entrepreneurial support (mean $=2.97$ ) was determined to be the greatest barrier, followed by lack of exposure (mean $=2.89)$, teaching methods (mean $=2.75)$, and lastly the syllabus $($ mean $=2.31)$. Appropriateness of the syllabus and course content barrier yielded the lowest mean score (2.31), demonstrating that it cannot be considered a barrier per se in entrepreneurship promotion.

Table 5: Descriptive statistics

\begin{tabular}{lll}
\hline Barrier & Mean & Standard Deviation \\
\hline Lack of entrepreneurial support & 2.97 & .88 \\
Lack exposure & 2.89 & .83 \\
Teaching methods & 2.75 & .89 \\
Syllabus & 2.31 & .87 \\
\hline
\end{tabular}

Overall, the results summarised in Table 4 indicate that theoretic entrepreneurship education syllabi seem appropriate for encouraging student entrepreneurship. Table 3 suggests that the appropriateness of theoretic entrepreneurship education syllabi (mean $=2.31$ ) when considered alongside appropriate teaching methods (mean 2.75) confirm universities' competences not only in teaching theory, but also as important vehicles for influencing trends, especially among students. This therefore supports the argument that universities are important change agents within society. Du Pre (2009) argues that the role of higher education, in particular, Universities of Technology (UoTs), is to encourage students to become entrepreneurs. It therefore can be concluded that the proposal of the National Development Plan - 
promoting entrepreneurship through higher education - therefore constitutes a valid policy position (Republic of South Africa, 2012). The Facebook example indicated earlier is an example of 'institutionalised entrepreneurship barriers' inherent in the higher education system, which authors such as Massad and Tucker (2009) bemoan as leading to lost opportunities towards entrepreneurship. In general, the findings of this research appear to corroborate past studies (Lennox, 2013; Rasmussen and Sorheim, 2006; Strydom and Adams, 2009; van der Walt and van der Walt, 2008). The underlying theme, however, is that universities could do more to improve entrepreneurship promotion. In this regard, two specific areas are suggested: improving entrepreneurial support and initiating programmes to enhance awareness.

RQ2: Are these barriers experienced differently across the student population?

Having found support for the EB model within the South African context, it was instructive to establish the nature of the barriers across the sample. This was particularly important given that university students are diverse in nature. It was insightful to segment the respondents into smaller homogenous groups by means of cluster analysis (Field, 2009). The mean scores for each of the four latent variables (Table 3) and gender were used as the basis for segmentation. Cluster analysis yielded two distinct categories. From studying Table 4, gender was observed to account for the most variation between clusters. For instance, Cluster M1 consisted of mostly female respondents (60 per cent) and male respondents were a majority (68 per cent) in Cluster M2. Another interesting finding was that for all the four barriers, mean scores of Cluster M1 were much greater than Cluster M2. The analysis of variance (ANOVA) confirmed that there was a difference between the mean scores between Clusters M1 and M2 $(p<.05)$.

Table 6: Entrepreneur clusters

\begin{tabular}{lllll}
\hline Barrier & $\begin{array}{l}\text { M1 } \\
\text { (Sceptics) } \\
\text { N=160 }\end{array}$ & $\begin{array}{l}\text { M2 } \\
\text { (Optimists) } \\
\mathbf{N = 7 5}\end{array}$ & F & p-value \\
\hline Gender & $60 \%$ Female & $68 \%$ Male & & \\
Exposure & 3.26 & 2.11 & 128.26 & $p<.005$ \\
Support & 3.32 & 2.20 & 102.08 & $p<.005$ \\
Teaching & 3.06 & 1.96 & 99.94 & $p<.005$ \\
methods & & & & \\
Syllabus & 2.64 & 1.62 & 84.583 & $p<.005$ \\
\hline
\end{tabular}

The above results suggest that respondents belonging to M1 (mostly female participants, about 60 per cent) experience entrepreneurship barriers relatively more than individuals in M2 (mostly male respondents).Similar to the composite sample (Table 5), lack of support, as experienced by both Clusters M1and M2 (Table 6), was also observed to be the most significant barrier (mean = 3.26). Lack of exposure ranked as the second highest barrier, followed by teaching methods and lastly syllabus. The consistent pattern of barriers, as observed in the entire sample as well as within individual clusters, provides justification of the significance of these barriers. Closer inspection revealed that respondents belonging to M1 exhibited relatively more negative attitudes and scepticism towards entrepreneurship, and therefore this cluster of respondents were named Sceptics. At the same time, clusterM2 respondents seemed relatively more engaged in entrepreneurial activities, albeit exhibiting some reservations towards entrepreneurial activities. Accordingly, this category was named Optimists. For all the four barriers of the theory of barriers to entrepreneurship promotion(Yaghoubi, 2010) tested, mean scores observed within the Sceptics and Optimists clusters as measured by ANOVA differed significantly $(p<.05)$.

Sceptics: This cluster contained a significant majority of respondents ( $n=160)$; it was mostly constituted by female respondents. There was overwhelming evidence that individuals falling within this cluster demonstrated tendencies of scepticism towards entrepreneurship. Further analysis revealed that these respondents had been less exposed to business and entrepreneurship. For instance, some 84 per cent of female respondents reported that no close relative or friend of theirs had ever been an entrepreneur or operated a business. Their negative attitudes towards entrepreneurship in general and disinterest in choosing entrepreneurship as a career option can be best understood by reviewing the works ofAldrich, Renzulli and Langton (1998) and Carr and Sequeira (2007). The latter authors in particular, investigated entrepreneurial intentions as influenced by intergenerational relations. They found that prior exposure to a family owned and operated business has a positive effect on the formation of attitudes towards starting a business(Carr and Sequeira, 2007:1095).This argument is compelling, especially because 
entrepreneurship is a social phenomenon, and social norms greatly influence social behaviour and actions, including starting a business (Aldrich et al., 1998).

Also by considering entrepreneurship as a social interaction(Solymossy and Hisrich, 1998), gender roles and relationships clearly play a role in entrepreneurial attitudes and intentions, as is evidenced by the majority of respondents in this cluster being female. Gaidzanwa (2003)demonstrates that women within the African context are historically marginalised, and only recently have begun to access the same opportunities in family, education, and society as men. Gaidzanwa (2003) further argues that because of the colonial legacy and African cultural practices, women in Africa were historically and to a certain extent are still being trained to perform domestic duties only. She further demonstrates that even the training and education they receive reflects this social arrangement. It is therefore reasonable to argue that entrepreneurship will not be the most preferred career choice for most African women. Further evidence of this is reflected in the Global Entrepreneurship Management statistics $(2005 ; 2011)$ which indicate that engaging in entrepreneurship is relatively less accessible to female youths compared to their male counterparts, who tend to be more adventurous. It was found that, out of 100 South African women, only four were owner-managers of existing businesses; this is in stark contrast to a ratio of 10 in every 100 males in business ownership(Global Entrepreneurship Monitor, 2005; 2011).

Optimists: The Optimists' cluster was comprised of 75 respondents. Approximately 68 per cent of these were males. As shown in Table 6, the means scores for all four barriers were comparatively lower than those of the Sceptics category. Of these however, syllabus (mean $=1.62$ ) and teaching methods barriers (mean $=1.96$ ) were observed to have the lowest mean scores. Given the EB questionnaire item scoring on the Likert scale $(1=$ Strongly Disagree; $5=$ Strongly Agree), very low mean scores indicate that the respondents do not consider these two factors to be barriers, since they disagree with the statement that they are barriers. The above therefore suggests that the members of this cluster inherently have positive perceptions and attitudes towards entrepreneurship (Aldrich et al., 1998). It was also observed that a majority of the Optimists were male (68 per cent), and that they indicated a greater willingness to engage in business ventures. For instance, they exhibited more knowledge and expertise about starting and running businesses. A plausible explanation for these attributes displayed could be gender, as has been previously asserted by many authors including Gaidzanwa (2003), who argue that men tend to be more adventurous and out-going as a result of their upbringing and education. Following this line of thought, it is therefore not surprising that entrepreneurship was viewed much more favourably as a possible career choice by male respondents than female. Considering that exposure and support were the greatest barriers experienced by this cluster, a conducive environment in which they are continually exposed to existing business practices will enhance this group's tendency to become entrepreneurial. As such, universities could encourage these students to participate in starting businesses. Initiatives such as entrepreneurial incubators, technology stations, and university spin-offs (USOs) are possible vehicles which could provide the required practical training(Greve, 1995; Jones and English, 2005; Makgosa and Ongori, 2012; Massad and Tucker, 2009; Strydom and Adams, 2009; Yaghoubi, 2010).

\section{Conclusion}

The purpose of the study was to identify barriers limiting students' participation in entrepreneurial activities. Drawing from the literature, a multitude of entrepreneurship barriers were identified and tested. The findings of this research support the theory of entrepreneurship barriers (Yaghoubi, 2010). Another important finding, corroborating past research (e.g., Greve, 1995; Massad and Tucker, 2009; Strydom and Adams, 2009; van der Walt and van der Walt, 2008) was that universities were found to be important catalysts in developing entrepreneurial attitudes, as found in previous studies. Therefore, as proposed by South Africa's National Development Plan, universities' participation in promoting entrepreneurship should not be discounted(Republic of South Africa, 2012). It is for this reason that many institutions of higher learning have introduced entrepreneurship research units, such as the University of Cape Town's Centre for Innovation and Entrepreneurship (Global Entrepreneurship Monitor, 2005). On the other hand, lack of exposure and lack of entrepreneurial support were identified to be the most significant barriers. Given that the most important barrier identified related to lack of entrepreneurial support, it would appear that academics, for the most part, are not living up to the expectations of entrepreneurship promotion. In line with Du Pre (2009), education appears to be more theoretical, suggesting an urgent need to incorporate practical business training. In this regard, Massad and Tucker (2009) have shown that curriculum improvements will help address the entrepreneurship problem. Some recommended initiatives that South African universities should consider the inclusion of 
business simulations utilising business kiosks on campuses or even operating businesses on the Internet such as operating retail services on eBay within their curricula. Students, on the other hand, are mostly concerned with passing, and not necessarily learning new knowledge. As a result, students are not as exposed to business as they could and should be.

Overall, the findings suggest an important relationship between entrepreneurship education and entrepreneurial promotion. It can therefore be concluded that education plays an important role in fostering entrepreneurial attitudes, which in turn influences entrepreneurial promotion(Global Entrepreneurship Monitor, 2011; Greve, 1995; Rasmussen and Sorheim, 2006; Strydom and Adams, 2009). Combining practical business and incubation support tailored to the specific needs of students will likely strengthen entrepreneurial activity and the success rates of student-driven enterprises. Given the strategic importance of the subject matter for both researchers and policymakers, future research could consider the impact of practical teaching methods, such as the inclusion of practical business projects (e.g. eBay businesses) or utilising technologies (e.g. Second Life) in teaching business. Another interesting area of study could be the empirical testing of the link between education and entrepreneurial intentions. Future researchers could also consider further exploring the different typologies of not only youths but also the general population in terms of entrepreneurship barriers experienced.

Managerial Implications: There has been significant growth in universities offering entrepreneurshiprelated programmes. Clearly, universities' increased commitment towards fostering entrepreneurship appears to be both the cause and result of rapidly growing research into entrepreneurship education, which tries to address the question of how university training can meaningfully contribute towards the creation of entrepreneurial societies. In South Africa, these efforts have resulted in numerous entrepreneurship support structures, including government agencies such as the National Youth Development Agency (NYDA) and Small Enterprises Development Agency (SEDA), as well as a variety of entrepreneurship courses. South African universities offer entrepreneurship courses within the classroom, as well as practical training, including technology stations, incubators, and business clinics outside the classroom. The objectives of these initiatives are to encourage, promote, and support studentdriven enterprises. While these efforts have been quite successful in supporting entrepreneurship, they tend to focus only on macro-level issues, i.e. creating national entrepreneurship infrastructure. However, this study has shown that, whilst these programmes are important, they are not readily utilised by university graduates. Students appear not to be interested or fully prepared to engage in entrepreneurial activities. Consequently, the focus of the study was on identifying barriers that discourage student entrepreneurship. It was observed that students experience a lack of exposure to business and are not fully supported by institutions of higher learning to develop their business ideas into practice.

Our findings suggest that theoretical and practical entrepreneurial education plays an important role in fostering entrepreneurial intentions among students. University education empowers graduates to successfully plan, start, and operate a business in three phases: (1) idea development, (2) organising the founding of a firm, and (3) running a newly-established firm. As such, the contribution of universities is most significant in influencing the first two phases. Thus, the relevance of universities should be assessed by their efficacy to "train" their students into becoming self-sustaining entrepreneurs (Jones and English, 2005). The implications are that university curricula should be redesigned in order to stimulate an environment that is conducive to developing positive entrepreneurial attitudes. Particular emphasis should be placed on female students, who are observed as facing the greatest barriers in starting and running businesses. Incorporating real-life business training with theory will go a long way towards supporting entrepreneurial activity. Vehicles such as business incubators and entrepreneurshipmentorship programmes are also encouraged.

\section{References}

Aldrich, H. E., Renzulli, L. A. \& Langton, N. (1998). Passing on Privilege: resources provided by selfemployed parents to their self-employed children. Research in Social Stratification and Mobility. K. Leicht. Greenwich, CT, JAI.

Apps, P. (2011). Analysis - London riots point to wider risks of youth unrest. Retrieved 5 June 2013, from http://uk.reuters.com/article/2011/08/09/uk-britain-unrest-youth-idUKTRE7783G720110809.

Blumberg, B., Cooper, D. R. \& Schindler, P. S. (2011). Business Research Methods, 3rd European Edition. London, McGraw Hill. 
Carr, J. C. \& Sequeira, J. M. (2007). Prior family business exposure as intergenerational influence and entrepreneurial intent: A Theory of Planned Behaviour Approach. Journal of Business Research, 60, 1090-1098.

Chauke, A. (2011). ANC Youth League 'economic freedom' mass action: LIVE 27 October. from http://www.timeslive.co.za/politics/2011/10/27/anc-youth-league-economic-freedom-massaction-live-27-october.

Du, P. (2009). The place and role of Universities of Technology in South Africa. Bloemfontein, Durban University of Technology (on behalf of South African Technology Network).

Dulewics, V., Higgs, M. \& Slaski, M. (2003). Measuring emotional intelligence: content, construct and criterion related validity. Journal of Managerial Psychology, 18(5), 405-420.

Ebewo, P. E. \& Shambare, R. (2012). The reason business plans of start-up ventures are rejected by South African financiers: evidence from SIFE-TUT Harmony Fashion Design Business Challenge. Emerging Markets Conference of the International Management Research Academy (IMRA). London, 17-18 May 2012, IMRA.

Facebook.com. (2012). Histrory of Facebook. Retrieved 6 June 2012, from http://www.facebook.com/pages/History-of-Facebook/105185536206799.

Field, A. (2009). Discovering Statistics Using SPSS, 3rd Edition. Thousand Oaks, CA, Sage.

Gaidzanwa. (2003). Gender and Canon Formation: Women and Men and Literary Art in Africa. Mans. Accra, Ghana.

Gartner, W. B. (1988). Who is an entrepreneur is the wrong question. American Journal of Small Business, 13, 11-32.

Global Entrepreneurship Monitor. (2005). Global Entrepreneurship Monitor South African Report 2005, GEM. 2005.

Global Entrepreneurship Monitor. (2011). Global Entrepreneurial Monitor: South Africa 2011, GEM.

Greve, A. (1995). Networks and entrepreneurship - an analysis of social relations, occupational background, and use of contacts during the establishment process. Scandanavian Journal of Management, 11(1), 1-24.

Jones, C. \& English, J. (2005). A contemporary approach to entrepreneurship education. Journal of Education Training, 46(8/9), 416-423.

Kane, C. (2013). Spain Prime Minister sees hope for unemployment on day of protests. Retrieved 5 June 2013, from http://uk.reuters.com/article/2013/06/02/uk-spain-joblessidUKBRE95007L20130602?feedType=RSS\&feedName=businessNews.

Kesler, C. \& Hout, M. (2010). Entrepreneurship and immigrant wages in US labour markets: a multi-level approach. Social Science Research, 39, 187-201.

Lekoko, M. (2011). Students' perceptions regarding entrepreneurship education: a case of two universities in Botswana. Master of Technology in Entrepreneurship, Tshwane University of Technology.

Lennox, N. (2013). SA must up its entrepreneurial game. Retrieved 5 June 2013, from http://m.news24.com/fin24/Entrepreneurs/News/SA-must-up-its-entrepreneurial-game20130315.

Makgosa, R. \& Ongori, H. (2012). Perceptions of Entrepreneurial Behaviour in Botswana. International Journal of Learning \& Development, 2(3), 247-259.

Massad, V. J. \& Tucker, J. M. (2009). Using student managed businesses to integrate the business curriculum. Journal of Instructional Pedagogies, 1, 17-29.

Pallant, J. (2010). SPSS Survival Manual: A step by step guide to data analysis using SPSS, 4th Edition. Berkshire, UK, McGraw Hill.

Rasmussen, E. A. \& Sorheim, R. (2006). Action-based entrepreneurship education. Technovation, 26, 185194.

Republic of South Africa. (2012). The National Development Plan. D.o. Communication. Pretoria, Department of Communication.

Robertson, J. (2013). Eurozone unemploymengt reaches new record high in April." from http://www.bbc.co.uk/news/business-22727373.

Shambare, R. (2011). Using projects in teaching Introductory Business Statistics: the case of TUT Business School. African Journal of Business Management, 5(11), 4176-4184.

Shane, S. (2008). Why encouraging more people to become entrepreneurs is bad public policy. World Entrepreneurship Forum, 1-18.

Solymossy, E. \& Hisrich, J. (1998). Entrepreneurial dimensions: the relationship of individual, venture, and environmental factors to success. $\mathrm{PhD}$, Case Western Reserve University.

Sowetan. (2012). Universities produce wrong kind of graduates: analyst. Sowetan. Johannesburg. 
Statistics South Africa. (2013). Quarterly Labour Force Survey. Pretoria, StatsSA. Quarter 1 (January to March 2013).

Strydom, R. \& Adams, M. (2009). Evaluating the learning experience of undergraduate entrepreneurship students exposed to unconventional teaching approach: a South African case study. Southern African Journal of Entrepreneurship and Small Business Management, 2(1), 50-67.

UNDP. (2007). The legal empowerment of the Poor: Informal business. Cape Town, United Nations Development Programme.

van der Walt, R. \& van der Walt, S. J. (2008). Entrepreneurial training for Human Resources Practitioners and potential services rendered to small enterprises. Southern African Journal of Entrepreneurship and Small Business Management, 1(21-34).

Yaghoubi, J. (2010). Study barriers to entrepreneurship promtion in agriculture higher education. Procedia Social and Behavioral Sciences, 2, 1901-1905. 